\title{
Labour force sequences, unemployment spells and their effect on subjective well-being set points
}

\author{
Cara L. Booker \\ Institute for Social \& Economic Research, University of Essex \\ cbooker@essex.ac.uk \\ Amanda Sacker \\ Department of Epidemiology and Public Health, University College, London
}

(Received January 2013 Revised May 2013)

\section{Abstract}

Drawing upon recent psychological literature, we examine the effect of employment statuses pre- and post-unemployment on levels of subjective wellbeing (SWB), and the return to pre-unemployment levels, i.e. set points. Data came from the British Household Panel Survey. SWB was measured using the GHQ-12 and a question on life satisfaction; Employment status was self-reported. Multilevel, jointed, piecewise, growth curve regression models were used to explore associations by gender, specifically whether different labour force sequences produced different growth curves and rates of adaptation. Overall, there was a tendency for men and women to return to well-being set points for both outcomes. However, findings showed differences by labour force sequence and SWB measure. Women who experienced unemployment between spells of employment returned to their SWB set point at a faster rate of return for GHQ than for life satisfaction, while for men, the rates of return were similar to each other. Women who were employed prior to unemployment and then became economically inactive showed a return to their GHQ set point, but there was no return to their life satisfaction set point. Economically inactive participants preunemployment, who then gained employment, also showed a return to their wellbeing set point. After economic inactivity and then unemployment, only men experienced a significant increase in life satisfaction upon return to economic inactivity. The findings showed that following unemployment, return to subjective well-being set point was quicker for people who became employed than for people who became economically inactive. There were also differences in the return to SWB set point by type of economic inactivity upon exiting unemployment.

Keywords: labour force status; unemployment; subjective well-being; set points 


\section{Introduction}

The subjective well-being (SWB) of the population is one of the many measures that are used to compare and rank countries. The Gallup World Poll has collected well-being measures as well as other socio-demographic and political characteristics from over 120 countries (Deaton, 2008; OECD, 2010). This information has been used in reports and news stories that declare the "happiest country in the world" and in research which examines why there are country differences and what factors are most associated with better SWB (Deaton, 2008; OECD, 2010, 2011).

Subjective well-being is composed of three distinct domains (1) Emotional responses including positive and negative affect, (2) Domain specific satisfaction and (3) Overall life satisfaction (Diener, 2000; Diener, Suh, Lucas, \& Smith, 1999). These domains have been widely examined with respect to various risk factors and moderators. However, researchers tend to focus on only one domain at a time (i.e. either life satisfaction or negative affect). Psychometric analysis of measures of these domains have shown them to be distinct constructs that are fairly independent and in some cases inversely correlated (i.e. positive and negative affect) (Diener \& Emmons, 1984; Diener, Suh, Lucas, \& Smith, 1999).

The hedonic treadmill, a theory that all individuals have a neutral level of happiness and that that they return to this equilibrium level, or "set point" after different life events was first postulated by Brickman and Campbell (1971). More recently, empirical and theoretical developments have contributed to the debate of the true stability of SWB, e.g. whether major or minor life events can have permanent effects on SWB, and whether the SWB domains have differing set points (Diener, Lucas, \& Scollon, 2006; Headey, 2006, 2008a, 2008b; Headey \& Wearing, 1992). While early research utilised cross-sectional data, current research has focused on using longitudinal cohort and panel data to assess the stability of SWB and the permanence of SWB set points (Clark, Diener, Georgellis, \& Lucas, 2008; Clark \& Georgellis, 2010; Clark, Georgellis, \& Sanfey, 2001; Frederick \& Loewenstein, 1999; Lucas, 2005, 2007a, 2007b; Lucas, Clark, Georgellis, \& Diener, 2003). A revision of the hedonic treadmill theory, by Diener, Lucas and Scollon (2006) incorporated the findings from empirical evidence leading to changes in five assumptions of the theory. The first revision is that set points are not neutral as stated by the hedonic treadmill: more often than not, people are happy and positive (Diener, Lucas, \& Scollon, 2006). Secondly, there is variation in set points between individuals. Thus some people may have higher levels of well-being than others, rather than all individuals having the same, neutral, set point (Diener, Lucas, \& Scollon, 2006). Thirdly they proposed that there are multiple set points corresponding to the different dimensions of SWB and the direction of long-term trends can differ dependent on the dimension (Diener, Lucas, \& Scollon, 2006). Fourthly, they postulate that individuals' set points can be altered. This is a major change from the hedonic treadmill which says that individuals cannot modify their overall levels of happiness. However Diener, Lucas and Scollon (2006) provide both cross-sectional and longitudinal data that show this to be untrue. Finally, they state that adaptation to life events varies across individuals (Diener, Lucas, \& Scollon, 2006). It is the last two points that are the main focus of this study.

If we take it as a given that the subjective wellbeing set points of individuals can be changed, do certain life events such as unemployment cause these changes or do people adapt to these events and return to their set point? There have been many studies that have examined set points and whether there are any changes to them with respect to different life events such as marriage (Diener, Lucas, \& Scollon, 2006; Lucas, 2007a; Lucas, Clark, Georgellis, \& Diener, 2003; Luhmann \& Eid, 2009), divorce (Diener, Lucas, \& Scollon, 2006; Lucas, 2005, 2007a; Lucas, Clark, Georgellis, \& Diener, 2003; Luhmann \& Eid, 2009), unemployment (Diener, Lucas, \& Scollon, 2006; Lucas, Clarke, Georgellis, \& Diener, 2004; Luhmann \& Eid, 2009) and disability (Lucas, 2007b; Lucas, Clark, Georgellis, \& Diener, 2003). With respect to unemployment, people do appear to reset their set point. That is, SWB does not return to preunemployment levels, i.e. measures of SWB postunemployment are consistently lower than the measurements of SWB prior to unemployment.

However there are a few issues that previous studies have not addressed which may affect whether there is a return to a SWB set point. First, pre- and post-unemployment labour force status has not been examined. A recent study showed that there were differential effects on GHQ scores 
during unemployment by pre-unemployment status (Booker \& Sacker, 2011). They found that participants who had multiple spells of unemployment following economic inactivity experienced increased distress with each spell. This was in opposition to participants who experienced unemployment following employment whose distress decreased with each unemployment spell (Booker \& Sacker, 2011). These effects suggest that the labour force status both pre- and postunemployment may have an effect on whether individuals will return to their SWB set point. Examining the effects of economic inactivity on SWB may also serve to explore the effects of hidden unemployment (Beatty, Fothergill, \& Macmillan, $2000)$, i.e. those who report being out of the labour force rather than report being unemployed, or those who do not meet the International Labour Organization measures of unemployment.

Additionally, the type of economic inactivity that one is involved with may further impact the return to SWB. The rate of return for someone who is retired may be different than the rate of return for someone who is taking care of their family or long-term sick. Exploration of this topic has not previously been examined and may have implications for future policy.

The third topic is that studies to date have only looked at life satisfaction as their measure of SWB. As Diener and colleagues (2006) showed, there are different set points for different domains of SWB and individuals may adapt differently for each. We test this theory by comparing two measures of SWB, the 12-item General Health Questionnaire (GHQ-12) (D. Goldberg \& Williams, 1991) and overall life satisfaction.

Finally, there is some ambiguity in the literature regarding time given to return to the SWB set point. Research conducted by Lucas et al. (2004) looked at short-term adaptation, i.e. a return to set point 1-2 years after a life event, and found no return to set point. Other studies have looked at longer periods of adaptation with mixed findings (Clark \& Georgellis, 2010; Lucas, 2007a; Lucas, Clark, Georgellis, \& Diener, 2003). The current study makes no assumptions about whether there are improvements to well-being following unemployment nor the length of time needed to return to SWB set point. We address this and other topics by asking:
1. Do individuals return to their well-being set point after exiting unemployment? If so, how long does it take to return to that set point?

2. Does the labour force sequence experienced prior to and post unemployment influence whether individuals return to their set point, and if so, does the time needed to return differ by sequence?

3. Does the type of economic inactivity experienced prior to or post unemployment influence the return to SWB set point for individuals, and if so, how do rates of return differ by economic inactivity state?

\section{Methods}

\section{Participants}

The data used for this study come from the British Household Panel Survey (BHPS), a nationally representative longitudinal population survey, which began in 1991 with over 10,000 individuals in about 5,500 households (Taylor, with Brice, Buck, \& Prentice-Lane, 2009). A detailed description of the sampling procedure and survey methods is provided by Taylor et al. (2009). Eighteen years of data, 1991-2008, were included in this study. Only participants who had experienced at least one spell of unemployment were included in the analyses, reducing the sample to 1,491 persons with 19,505 person-year observations.

\section{Measures \\ Labour force status}

Self-reported labour force status was obtained from annual surveys. The data allowed for in-depth investigation of the different employment states. Participants who reported that they were employed or self-employed were categorised as employed; all others (i.e. retired, maternity leave, family care, long-term illness, full-time education and other) were categorized as economically inactive. The International Labour Organisation definition of unemployment was used to identify unemployed participants, these were people who were out of work but were actively looking for work within the past month.

\section{Subjective well-being}

The 12-item General Health Questionnaire (GHQ-12) was used as the measure of psychological well-being. The GHQ-12 has been validated to screen for minor psychiatric morbidity, specifically distress and anxiety (D. Goldberg \& Williams, 1988; D. P. Goldberg et al., 1997). A continuous scoring methodology was used where the scores ranged 
from 0-36. The cut-off for determination of a case with this scoring method is 12 (D. P. Goldberg et al., 1997). For the analysis, scores were reversed so that higher scores indicate better well being, and a case is determined by a score of 24 or less.

In order to account for natural time trends in GHQ scores, annual individual scores were centred around the year's grand mean (i.e. everyone in the study regardless of whether they experienced unemployment or not). These scores were then standardized to the overall grand mean (i.e. the mean GHQ score for everyone over the 18 waves of data).

One question was used as the measure of overall life satisfaction. This question was scored on a 7-point scale ranging from a low of "Completely dissatisfied" to a high of "Completely satisfied."

\section{Control variables}

Pre-study unemployment, household income, limiting long-term illness, age and gender, were included as control variables. Pre-study unemployment was a dichotomous indicator of whether individuals had experienced any bouts of unemployment prior to beginning their participation in the BHPS. Annual household income was adjusted for inflation, equivalised for household composition using the OECD modified equivalence scale, log transformed and then standardised to the study mean.

Limiting long-term illness (LLTI) status was a dichotomous variable determined from two questions. The first question asked "Do you have any of the health problems or disabilities listed on this card?" If the participant answered yes to this question then they are asked "Does your health in any way limit your daily activities compared to most people of your age?" In two waves, these questions were not asked and alternatives were chosen. Those questions asked "During the past 4 weeks, have you had any of the following problems with your work or other regular daily activities as a result of your physical health? Have you...been limited in the kind of work or other activities?" and "During the past 4 weeks, have you had any of the following problems with your work or other regular daily activities as a result of any emotional problems. Have you...cut down on the amount of time you spend on work or other activities?" Participants who experienced any limiting impairment/disability were categorized as having a LLTI, while all others were categorised as not having a LLTI.
To control for possible cohort effects, age was calculated as the participant's age in 1991 and standardized to have a mean of 0 and a standard deviation of 1 . A squared term of standardised age accounted for differential and non-linear relationships between subjective well-being and age. Men were designated as the reference category for gender.

\section{Analytic Scheme}

Three-piece jointed growth curve models were developed to analyse the effects of unemployment on subjective well-being. The three pieces correspond to the period before unemployment, Stage 1; the period of unemployment, Stage2; and the years following unemployment, Stage 3. The overall model did not distinguish between labour force statuses in Stages 1 or 3. Four separate versions of this model were then run which selected samples based on differing labour force status sequences prior to and after unemployment. The four labour force sequences are:

1) Employed - Unemployed - Employed (EUE),

2) Employed - Unemployed - Inactive (EUI),

3) Inactive - Unemployed - Employed (IUE), and

4) Inactive - Unemployed - Inactive (IUI).

These overall and sequence-specific models were analysed using multilevel, jointed, piecewise, growth curve regression models (Bollen \& Curran, 2006; Chou, Yang, Pentz, \& Hser, 2004), with annual measurements (Level 1) nested within individuals (Level 2), with SAS/STAT software Version 9.1. (SAS Institute Inc., 2003). Details of models can be found in Table S1 in the supporting on-line information. A benefit of using multilevel regression is the ability to model data that is unbalanced and has unequally spaced measurement occasions as is common in panel studies. Only the first unemployment spell was examined; if a participant experienced a second unemployment spell all data were censored beginning with the first year of the second unemployment spell. Only consecutive years of employment status are included in the analysis. For example, if a participant was economically inactive for the first three years of their involvement in the study, then became employed for two years and then became unemployed, the three years of economic inactivity are censored, only the two years of employment immediately before the years of unemployment are included in the analysis. Similarly, if a participant is employed, becomes 
unemployed, returns to employment and then becomes economically inactive three years following their re-employment all years of economic inactivity following re-employment are censored. Continuously employed or economically inactive participants were censored if a change in employment status or attrition occurred.

The two growth curve parameters specified for each of the three periods include a linear and quadratic effect of time. The model is shown below:

$Y_{i j}=t_{1 j i j} b_{1 j}+t_{1 i j}^{2} b_{1 j}+t_{2 i j} b_{2 j}+t_{2 i j}^{2} b_{2 j}+t_{3 j} b_{3 j}+t_{3 i j}^{2} b_{3 j}+\sum b_{n i j} X_{n}$ $+\varepsilon_{\mathrm{ij}}+\mu_{\mathrm{i}}$

where $Y$ is the outcome of either GHQ-12 score or overall life satisfaction score, $t$ represents the repeated time measures in each stage, $t^{2}$ is a quadratic term for the time variable $t, \varepsilon_{i j}$ is the random effect for individual $i$ at measurement occasion $j$, and $\mu_{i}$ is the random intercept for individual $i$. The parameters $\Sigma b_{n i j} X_{n}$ represent the covariates included in the model: age, age squared, gender and pre-study unemployment. Variable $t_{1}$ is equal to 0 in the first wave of stage one and then increases by one for all waves of stage 1 and then is constant at the last value of stage 1 for the remaining 2 stages. Variable $t_{2}$ is equal to 0 during stage 1 and is equal to 1 at the first wave of stage 2 and increases by one for every wave in that stage. Similar to $t_{1}, t_{2}$ remains constant throughout stage 3 . The coding for $t_{3}$ is similar to that for $t_{2}$. However $t_{3}$ continues to increase until the most recent wave of data collection or until the participant has dropped out, changed employment status or experienced a second unemployment spell, at which point they are censored from the analysis.

As a comparison to those who experienced unemployment, growth curve trends for participants who were continuously employed or continuously economically inactive were also modelled. There were 5,257 continuously employed participants with 42,655 person-years, and 4,260 continuously economically inactive participants with 27,248 person-year observations. In these models, a single stage was modelled together with the control variables previously described.

Where sample sizes allowed, growth curve regression models were estimated for specific economic inactivity states for the overall and EUI, IUE and IUI labour force sequences. Retirement, family care, full-time student and long-term sick states were modelled. In the case of IUI, the pre-unemployment economic inactivity was not broken down by economic inactivity status, only post-unemployment economic inactivity.

\section{Results}

\section{Descriptive Statistics}

Table 1 provides the baseline descriptive statistics for the men and women in this sample. The overall sample was equally divided by gender. Overall, $8 \%$ of men and $3 \%$ of women reported having been unemployed prior to enrolment in the study. The average age was 31.39 ( $S D=14.01$ ) for men and 31.16 $(S D=12.8)$ for women. Breakdown by labour force sequence showed that a greater proportion of men who experienced EUE and EUI reported pre-study unemployment than those who were economically inactive in Stage 1 ( $p$-value $=0.05)$, no significant differences were observed among women. EUI men had a higher mean age than EUE and IUE men, while IUE participants were the youngest for both men and women ( $p$-value $<0.0001$ ). There were no significant differences in GHQ-12 scores for men who experienced different labour force sequences and only marginal differences between IUI and IUE women ( $p$ value $=0.08$ ). There were no significant differences in life satisfaction or annual household income between participants with different labour force status sequences.

\section{Overall Trajectories}

The gender stratified parameter estimates are given in Table 2. A significant coefficient for the linear term indicates an increase or decrease in the SWB measure score, while a significant quadratic coefficient indicates that the rate of change was accelerating or decelerating. Overall, the acceleration/deceleration was small compared to the linear slopes.

The figures are based on a hypothetical exemplar respondent's employment history consisting of four years prior to unemployment (periods 1 to 4), two years of unemployment (periods 5 and 6), and the immediate four years after unemployment (periods 7 to 10). The SWB set point is defined as the mean GHQ12 or life satisfaction score pre-unemployment, periods 1 to 4 . In order to illustrate the impact of different labour force sequences on SWB set points, we estimate the time taken to return to this exemplar respondent's mean pre-unemployment SWB score after exiting unemployment. 
Table 1. Baseline Descriptive Statistics, by Gender *

\begin{tabular}{|c|c|c|c|c|c|c|c|c|c|c|c|}
\hline & \multicolumn{2}{|r|}{$\begin{array}{l}\text { Overall } \\
(n=1491)\end{array}$} & $\begin{array}{l}\text { Employ } \\
\qquad \operatorname{Re}-\end{array}$ & $\begin{array}{l}\text { d - Unemploye } \\
\text { aployed (EUE) } \\
(n=674)\end{array}$ & Employ & $\begin{array}{l}\text { - Unemploye } \\
\text { ctive (EUI) } \\
(n=246)\end{array}$ & $\begin{array}{r}\text { nactive } \\
\text { Em }\end{array}$ & $\begin{array}{l}\text { - Unemployec } \\
\text { oloyed (IUE) } \\
(n=300)\end{array}$ & \multicolumn{2}{|c|}{ Inactive - Unemployed - } & $p$-value ${ }^{+}$ \\
\hline \multicolumn{12}{|l|}{ Men } \\
\hline Pre-Study Unemployment, \% Yes & 8 & -- & 9 & -- & 12 & -- & 5 & -- & 3 & -- & 0.05 \\
\hline Limiting Long-term Iliness, \% Yes & 7 & -- & 4 & -- & 3 & -- & 7 & -- & 22 & -- & $<0.0001$ \\
\hline Age, mean $(95 \% \mathrm{Cl})$ & 31.39 & $(30.39,32.40)$ & 32.06 & $(30.83,33.29)$ & 40.61 & $(38.12,43.09)$ & 20.53 & $(18.51,22.55)$ & 36.27 & $(33.69,38.85)$ & $<0.0001$ \\
\hline GHQ-12 Score, mean $(95 \% \mathrm{Cl})$ & 25.84 & $(25.47,26.20)$ & 26.05 & $(25.56,26.54)$ & 25.41 & $(24.40,26.43)$ & 26.09 & $(25.29,26.90)$ & 24.85 & $(23.80,25.90)$ & 0.16 \\
\hline Life Satisfaction Score, mean $(95 \% \mathrm{Cl})$ & 5.30 & $(5.12,5.48)$ & 5.16 & $(4.91,5.41)$ & 5.60 & $(4.98,6.22)$ & 5.30 & $(4.96,5.64)$ & 5.63 & $(5.14,6.11)$ & 0.29 \\
\hline Annual Household Income $(95 \% \mathrm{Cl})$ & 0.04 & $(0.04,0.05)$ & 0.05 & $(0.04,0.06)$ & 0.04 & $(0.03,0.06)$ & 0.04 & $(0.02,0.05)$ & 0.03 & $(0.01,0.05)$ & 0.51 \\
\hline \multicolumn{12}{|l|}{ Women } \\
\hline Pre-Study Unemployment, \% Yes & 3 & -- & 3 & -- & 2 & -- & 1 & -- & 1 & -- & 0.87 \\
\hline Limiting Long-term Iliness, \% Yes & 13 & -- & 8 & -- & 11 & -- & 10 & -- & 23 & -- & $<0.0001$ \\
\hline Age, mean $(95 \% \mathrm{Cl})$ & 31.16 & $(30.24,32.08)$ & 33.02 & $(31.58,34.47)$ & 34.69 & $(32.73,36.64)$ & 22.63 & $(20.69,24.56)$ & 32.60 & $(30.83,34.37)$ & $<0.0001$ \\
\hline GHQ-12 Score, mean $(95 \% \mathrm{Cl})$ & 24.82 & $(23.34,24.26)$ & 24.05 & $(23.29,24.81)$ & 24.03 & $(23.02,25.05)$ & 24.47 & $(23.46,25.48)$ & 22.65 & $(21.72,23.59)$ & 0.04 \\
\hline Life Satisfaction Score, mean $(95 \% \mathrm{Cl})$ & 5.15 & $(4.88,5.21)$ & 5.06 & $(4.74,5.38)$ & 5.30 & $(4.90,5.71)$ & 4.97 & $(4.66,5.29)$ & 4.96 & $(4.63,5.28)$ & 0.56 \\
\hline Annual Household Income $(95 \% \mathrm{Cl})$ & 0.05 & $(0.05,0.06)$ & 0.05 & $(0.04,0.06)$ & 0.06 & $(0.05,0.08)$ & 0.04 & $(0.02,0.06)$ & 0.06 & $(0.05,0.08)$ & 0.20 \\
\hline
\end{tabular}

${ }^{+} \mathrm{p}$-value for Pre-Study Unemployment and Limiting Long-term Illness based on $\mathrm{X}^{2}$; $\mathrm{p}$-value for Age, GHQ-12, Life Satisfaction and Annual Household Income based on least squares mean comparisons 
Table 2. Overall Growth Models, by subjective well-being outcome and gender

\begin{tabular}{|c|c|c|c|c|c|c|c|c|}
\hline & \multicolumn{4}{|c|}{ GHQ } & \multicolumn{4}{|c|}{ Life Satisfaction } \\
\hline & \multicolumn{2}{|l|}{ Men } & \multicolumn{2}{|l|}{ Women } & \multicolumn{2}{|l|}{ Men } & \multicolumn{2}{|l|}{ Women } \\
\hline & $\begin{array}{l}\text { Regression } \\
\text { Coefficient }\end{array}$ & SE & $\begin{array}{l}\text { Regression } \\
\text { Coefficient }\end{array}$ & SE & $\begin{array}{l}\text { Regression } \\
\text { Coefficient } \\
\end{array}$ & SE & $\begin{array}{l}\text { Regression } \\
\text { Coefficient } \\
\end{array}$ & SE \\
\hline Intercept & $25.43 * * * *$ & 0.27 & $24.21 * * * *$ & 0.33 & $5.57 * * * *$ & 0.20 & $4.91 * * * *$ & 0.24 \\
\hline \multicolumn{9}{|l|}{ Pre- } \\
\hline \multicolumn{9}{|l|}{ Unemployment } \\
\hline Linear & -0.03 & 0.09 & -0.06 & 0.10 & -0.02 & 0.03 & 0.02 & 0.03 \\
\hline Quadratic & 0.01 & 0.01 & -0.00 & 0.01 & 0.00 & 0.00 & -0.00 & 0.00 \\
\hline \multicolumn{9}{|l|}{$\begin{array}{l}\text { Unemployment } \\
\text { Spell }\end{array}$} \\
\hline Linear & $-0.28^{*}$ & 0.14 & $-0.99 * * * *$ & 0.23 & $-0.19 * * *$ & 0.05 & $-0.21 * *$ & 0.07 \\
\hline Quadratic & 0.04 & 0.02 & $0.26 * *$ & 0.08 & 0.02 & 0.01 & $0.05^{*}$ & 0.02 \\
\hline \multirow{2}{*}{\multicolumn{9}{|c|}{$\begin{array}{l}\text { Post- } \\
\text { Unemployment }\end{array}$}} \\
\hline & & & & & & & & \\
\hline Linear & $0.40 * * * *$ & 0.07 & $0.43 * * * *$ & 0.09 & $0.08 * * * *$ & 0.02 & $0.09 * * * *$ & 0.03 \\
\hline Quadratic & $-0.02 * * *$ & 0.00 & $-0.02 * * *$ & 0.01 & $-0.00 *$ & 0.00 & $-0.00 *$ & 0.00 \\
\hline Age & $-0.58 * * * *$ & 0.14 & -0.24 & 0.17 & -0.02 & 0.04 & -0.02 & 0.05 \\
\hline Age Squared & $0.60 * * * *$ & 0.11 & $0.29 *$ & 0.14 & $0.12 * *$ & 0.04 & $0.09 *$ & 0.04 \\
\hline Pre-Study & -0.13 & 0.42 & -0.06 & 0.82 & -0.22 & 0.15 & -0.29 & 0.27 \\
\hline \multicolumn{9}{|l|}{ Unemployment } \\
\hline $\begin{array}{l}\text { Limiting Long-term } \\
\text { Illness }\end{array}$ & $-2.18 * * * *$ & 0.20 & $-3.14 * * * *$ & 0.22 & $-0.48 * * * *$ & 0.06 & $-0.41 * * * *$ & 0.06 \\
\hline $\begin{array}{l}\text { Annual Household } \\
\text { Income }\end{array}$ & 0.47 & 1.28 & $-2.97^{*}$ & 1.41 & 0.02 & 0.43 & $-1.49 * * *$ & 0.41 \\
\hline
\end{tabular}

${ }^{*}<0.05 ; * *<0.01 ; * * *<0.001 ; * * * *<0.0001$

Figure 1 shows the overall growth curves for GHQ (a) and life satisfaction scores (b) by gender, based on the parameter estimates in Table 2 . There were significant decreases in levels of SWB during unemployment and significant increases in the post-employment period for both men and women. Women experienced decelerating declines in SWB while unemployed and decelerating improvements post-employment, while men showed deceleration during post-unemployment only. These changes in well-being indicate that during the years of unemployment there was a decrease in GHQ scores, which levelled off over time for women, and during the period following unemployment there was improvement, albeit with deceleration, back towards the pre-unemployment GHQ score. Calculation of the increase in GHQ score postunemployment provided an estimate of 1.81 years for men and 4 years for women, for our exemplar respondents to return to their pre-unemployment GHQ score. 
Figure 1. Overall growth curve models $(--)$ for GHQ (a) and life satisfaction (b) by gender. Graph shows trend lines for continuously employed $(-\Delta-)$ and continuously economically inactive $(-x-)$ participants. The horizontal (--) is the set point line and the vertical (--) is where the curve crosses the set point line. The numbers along the $\mathrm{x}$-axis are years.

(a)

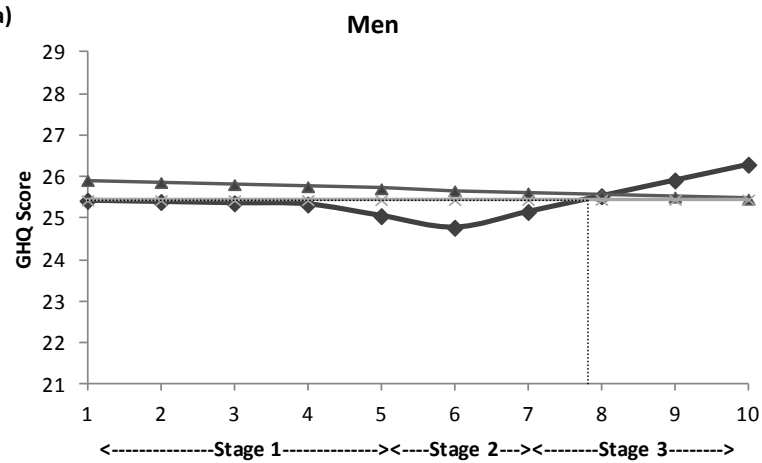

(b)

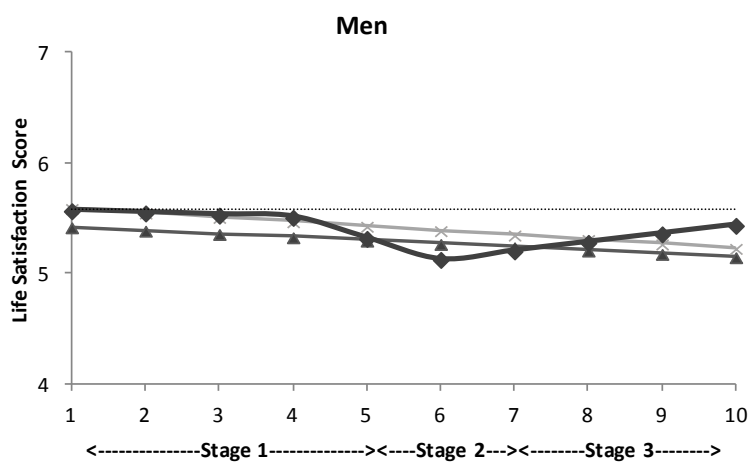

(a)

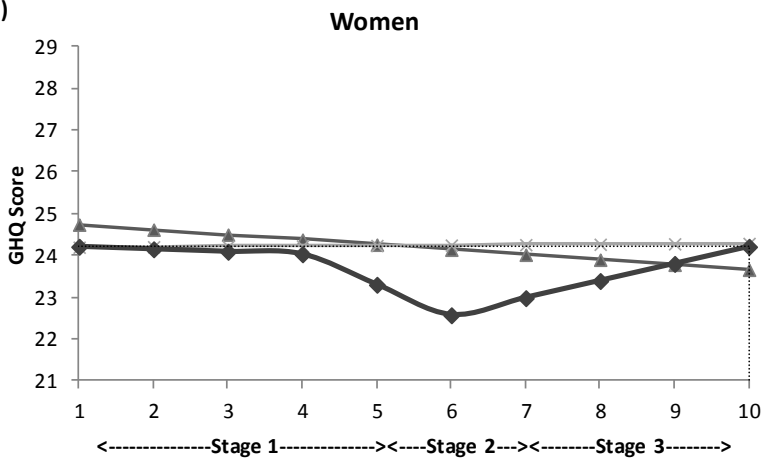

(b)

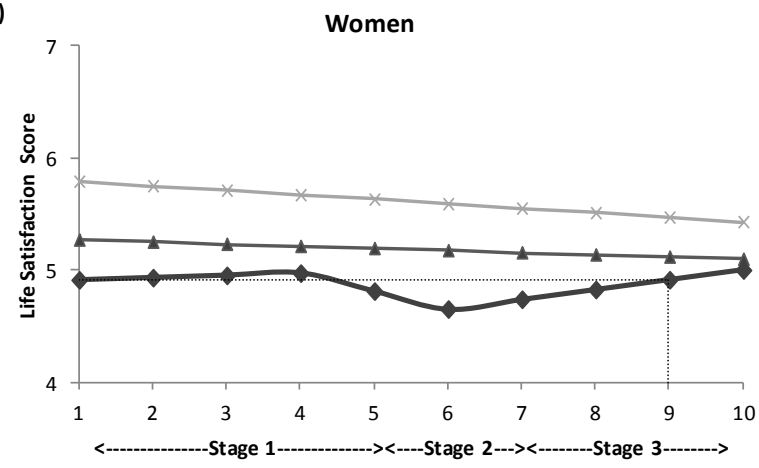

The growth curve of life satisfaction is similar to that for GHQ (Figure 1b). Life satisfaction reduced throughout the unemployment spell, for women there was a decreasing rate of change, and then a gradual increase again after exiting unemployment. The return to pre-unemployment life satisfaction took slightly longer than for GHQ, 5.71 years for our exemplar male respondent, but was shorter for our female exemplar at 2.99 years.

Figure 1 also includes comparison trajectories for participants who were continuously employed or economically inactive. (See Table S1a in the supporting on-line Appendix A for parameter estimates). For men, the GHQ trajectories were slightly better than for those who experienced unemployment with a rate of decrease across the years for those continuously employed, but a marginal increase across the years for the continuously economically inactive. Continuously employed women also had better GHQ scores than continuously economically inactive or those who experienced unemployment. Continuously employed women also experienced declines in their
SWB with their GHQ scores dipping below that of the continuously economically inactive after 6 years. Life satisfaction scores for men and women who were continuously economically inactive were slightly higher (better SWB) compared to the continuously employed. Life satisfaction decreased more quickly for those who were continuously economically inactive than for those who were continuously employed across the years. Levels of life satisfaction between the continuously employed and continuously economically inactive were more similar for men than for women.

\section{Trajectories by Labour Force Sequence}

While the overall curves show that there were significant non-linear trajectories for both SWB outcomes, we are interested in potential differential trajectories dependent on the labour force sequence experienced, specifically with respect to return to set point. Table 3 provides the gender specific parameter estimates for the different labour force sequences for each outcome. 
Both men and women who experienced a bout of unemployment in-between employment spells, EUE, had decreases in their SWB levels during unemployment, which then increased again on reemployment. These decreases in SWB during unemployment and subsequent increase upon reemployment gradually slowed down. Our male exemplar returned to GHQ set point after 5.19 years, while the return took 5.02 years for our female exemplar (Figures 2a and 3a).

In contrast to EUE, participants who experienced EUI had improvements in their GHQ score during economic inactivity only. Our male exemplar did not have a return to GHQ set point, while the return to GHQ set point was much shorter for our exemplar woman at 2.87 years (Figures $2 b$ and $3 b$ ).

Table 3. Growth models by labour force sequence, by subjective well-being outcome and gender ${ }^{+}$

GHQ

\begin{tabular}{|c|c|c|c|c|c|c|c|c|}
\hline & & & & & \\
\hline & \multicolumn{2}{|l|}{ Men } & \multicolumn{2}{|c|}{ Women } & \multicolumn{2}{|l|}{ Men } & \multicolumn{2}{|c|}{ Women } \\
\hline & $\begin{array}{l}\text { Regression } \\
\text { Coefficient }\end{array}$ & SE & $\begin{array}{l}\text { Regression } \\
\text { Coefficient }\end{array}$ & SE & $\begin{array}{l}\text { Regression } \\
\text { Coefficient }\end{array}$ & SE & $\begin{array}{l}\text { Regression } \\
\text { Coefficient }\end{array}$ & SE \\
\hline \multicolumn{9}{|l|}{ EUE } \\
\hline Intercept & 25.86 & 0.34 & $24.16^{* * * *}$ & 0.50 & $5.81 * * * *$ & 0.24 & $4.51 * * * *$ & 0.33 \\
\hline \multicolumn{9}{|l|}{ Employed (E) } \\
\hline Linear & -0.19 & 0.11 & -0.20 & 0.14 & -0.03 & 0.03 & -0.01 & 0.04 \\
\hline Quadratic & 0.01 & 0.01 & 0.01 & 0.01 & 0.00 & 0.00 & -0.00 & 0.00 \\
\hline \multicolumn{9}{|c|}{ Unemployed (U) } \\
\hline Linear & $-1.07 * * * *$ & 0.22 & $-1.49 * * * *$ & 0.36 & $-0.36^{* * * *}$ & 0.08 & $-0.23 *$ & 0.10 \\
\hline Quadratic & $0.24 * * * *$ & 0.06 & $0.41 * * *$ & 0.11 & $0.06 * *$ & 0.02 & 0.04 & 0.03 \\
\hline \multicolumn{9}{|c|}{ Re-Employed (E) } \\
\hline Linear & $0.46 * * * *$ & 0.09 & $0.55^{* * *}$ & 0.14 & $0.14 * * * *$ & 0.02 & 0.07 & 0.04 \\
\hline Quadratic & $-0.03 * * * *$ & 0.01 & $-0.03 * *$ & 0.01 & $-0.01 * * * *$ & 0.00 & -0.00 & 0.00 \\
\hline \multicolumn{9}{|l|}{ EUI } \\
\hline Intercept & $25.03 * * * *$ & 0.78 & $24.24 * * * *$ & 0.69 & $5.61 * * * *$ & 0.66 & $4.23 * * * *$ & 0.55 \\
\hline \multicolumn{9}{|l|}{ Employed (E) } \\
\hline Linear & 0.24 & 0.25 & -0.06 & 0.22 & -0.06 & 0.08 & -0.08 & 0.07 \\
\hline Quadratic & -0.00 & 0.02 & -0.01 & 0.02 & 0.00 & 0.01 & 0.00 & 0.01 \\
\hline \multicolumn{9}{|c|}{ Unemployed (U) } \\
\hline Linear & 0.16 & 0.34 & -0.57 & 0.48 & -0.14 & 0.13 & -0.22 & 0.17 \\
\hline Quadratic & -0.01 & 0.04 & 0.11 & 0.15 & 0.02 & 0.01 & 0.09 & 0.05 \\
\hline \multicolumn{9}{|l|}{ Inactive (I) } \\
\hline Linear & $0.70^{* * *}$ & 0.20 & $0.46^{*}$ & 0.19 & 0.03 & 0.06 & 0.02 & 0.06 \\
\hline Quadratic & -0.03 & 0.01 & -0.01 & 0.01 & 0.00 & 0.00 & 0.00 & 0.00 \\
\hline \multicolumn{9}{|l|}{ IUE } \\
\hline $\begin{array}{l}\text { Intercept } \\
\text { Inactive (I) }\end{array}$ & $25.36^{* * * *}$ & 0.67 & $25.48 * * * *$ & 0.84 & $5.14 * * * *$ & 0.49 & $6.59 * * * *$ & 0.52 \\
\hline Linear & -0.04 & 0.33 & 0.12 & 0.23 & -0.01 & 0.10 & -0.07 & 0.07 \\
\hline Quadratic & -0.02 & 0.06 & 0.01 & 0.02 & -0.01 & 0.02 & 0.01 & 0.01 \\
\hline \multicolumn{9}{|c|}{ (Table 3 cont'd) } \\
\hline \multicolumn{9}{|c|}{ Unemployed (U) } \\
\hline Linear & 0.04 & 0.42 & -0.75 & 0.59 & -0.25 & 0.15 & -0.09 & 0.17 \\
\hline Quadratic & 0.04 & 0.11 & 0.13 & 0.23 & 0.07 & 0.04 & 0.01 & 0.06 \\
\hline \multicolumn{9}{|l|}{ Employed (E) } \\
\hline Linear & 0.13 & 0.17 & $0.61 * *$ & 0.20 & 0.05 & 0.05 & $0.19 * * *$ & 0.05 \\
\hline Quadratic & -0.00 & 0.01 & $-0.05 * *$ & 0.02 & 0.00 & 0.00 & $-0.01 * *$ & 0.00 \\
\hline
\end{tabular}


(Table 3 cont'd)

IUI

\begin{tabular}{|c|c|c|c|c|c|c|c|c|}
\hline $\begin{array}{l}\text { Intercept } \\
\text { Inactive (I) }\end{array}$ & $24.82 * * * *$ & 1.00 & $22.83 * * * *$ & 0.79 & $5.94 * * * *$ & 0.77 & $4.85 * * * *$ & 0.57 \\
\hline Linear & -0.23 & 0.42 & 0.39 & 0.25 & -0.15 & 0.14 & 0.09 & 0.07 \\
\hline Quadratic & 0.02 & 0.05 & -0.01 & 0.03 & 0.01 & 0.02 & -0.01 & 0.01 \\
\hline \multicolumn{9}{|c|}{ Unemployed (U) } \\
\hline Linear & 0.08 & 0.38 & -0.98 & 0.57 & -0.23 & 0.14 & $-0.37 *$ & 0.19 \\
\hline Quadratic & -0.03 & 0.05 & 0.37 & 0.24 & 0.02 & 0.02 & 0.06 & 0.07 \\
\hline \multicolumn{9}{|l|}{$\begin{array}{l}\text { Return to } \\
\text { lactivity (I) }\end{array}$} \\
\hline Linear & 0.03 & 0.23 & 0.15 & 0.19 & $-0.15^{*}$ & 0.07 & 0.05 & 0.05 \\
\hline Quadratic & -0.00 & 0.02 & -0.01 & 0.02 & 0.01 & 0.00 & -0.00 & 0.00 \\
\hline
\end{tabular}

${ }^{*}<0.05 ;{ }^{* *}<0.01 ; * * *<0.001 ; * * *<0.0001$

${ }^{+}$Controlled for age, age squared, gender, limiting long-term illness, household income and pre-study unemployment; EUE $=$ Employed - Unemployed - Employed EUI = Employed - Unemployed - Inactive $;$ IUE = Inactive - Unemployed - Employed;

$I U I=$ Inactive - Unemployed - Inactive

Figure 2. GHQ by labour force sequence growth curve models for men (- $\downarrow-)$ : EUE (a), EUI (b), IUE (c) and IUI (d). Graph shows trend lines for continuously employed $(-\Delta-)$ and continuously economically inactive $(-x-)$ participants. The horizontal (--) is the set point line and the vertical (--) is where the curve crosses the set point line, where applicable. The numbers along the $x$-axis are years.
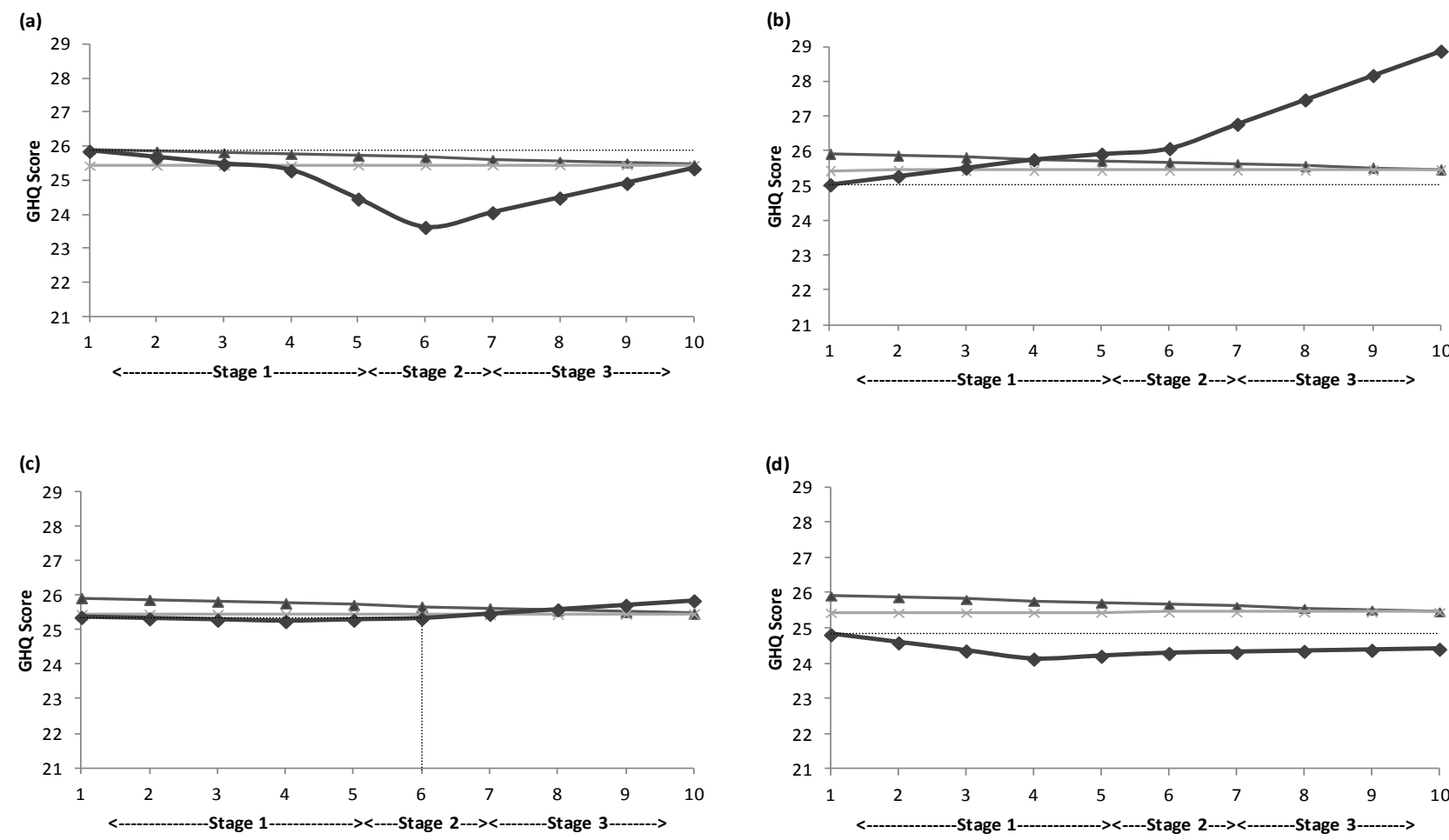

The GHQ score of participants who experienced IUE non-significantly changed during economic inactivity and unemployment, and then significantly increased with some deceleration on employment for women only (Figure 3c). The return to the GHQ

set point for our exemplar woman was between that for EUE and EUI participants at 2.04 years (Figure 3c). There were no significant changes in GHQ scores, at any stage, for participants who experienced IUI (Figures $2 \mathrm{~d}$ and $3 \mathrm{~d}$ ). 
Figure 3. GHQ by labour force sequence growth curve models for women (- $\downarrow-)$ : EUE (a), EUI (b), IUE (c) and IUI (d). Graph shows trend lines for continuously employed $(-\Delta-)$ and continuously economically inactive $(-x-)$ participants. The horizontal (--) is the set point line and the vertical (--) is where the curve crosses the set point line, where applicable. The numbers along the $x$-axis are years.

(a)

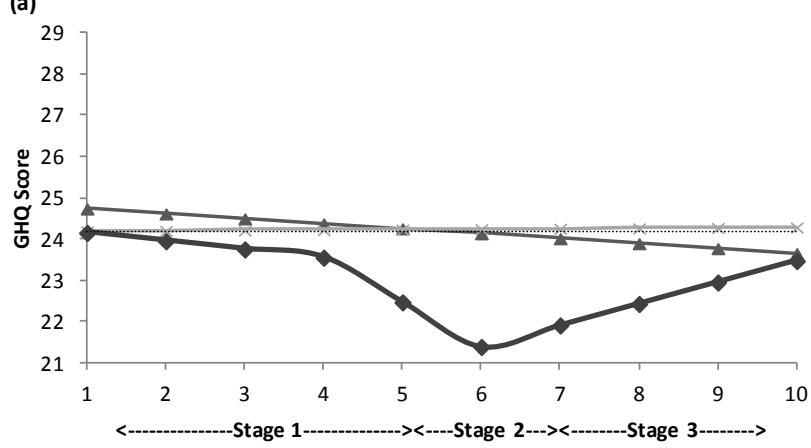

(c)

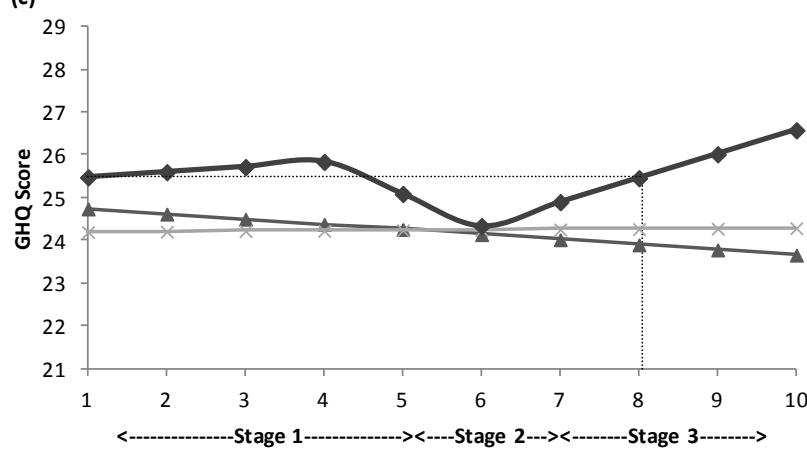

Three labour force sequences showed significant increases in life satisfaction postunemployment with gender differences, Table 3. Men who experienced EUE had deterioration during unemployment and an increase in life satisfaction when re-employed, with slowing down in the rates of deterioration or increase during both periods. Women experienced a decrease in life satisfaction while unemployed only. The return to life satisfaction set point took 5.07 years for men and 7 years for women (Figures $4 a$ and $5 a$ ).

There were no significant increases or decreases in life satisfaction at any stage for EUI participants.
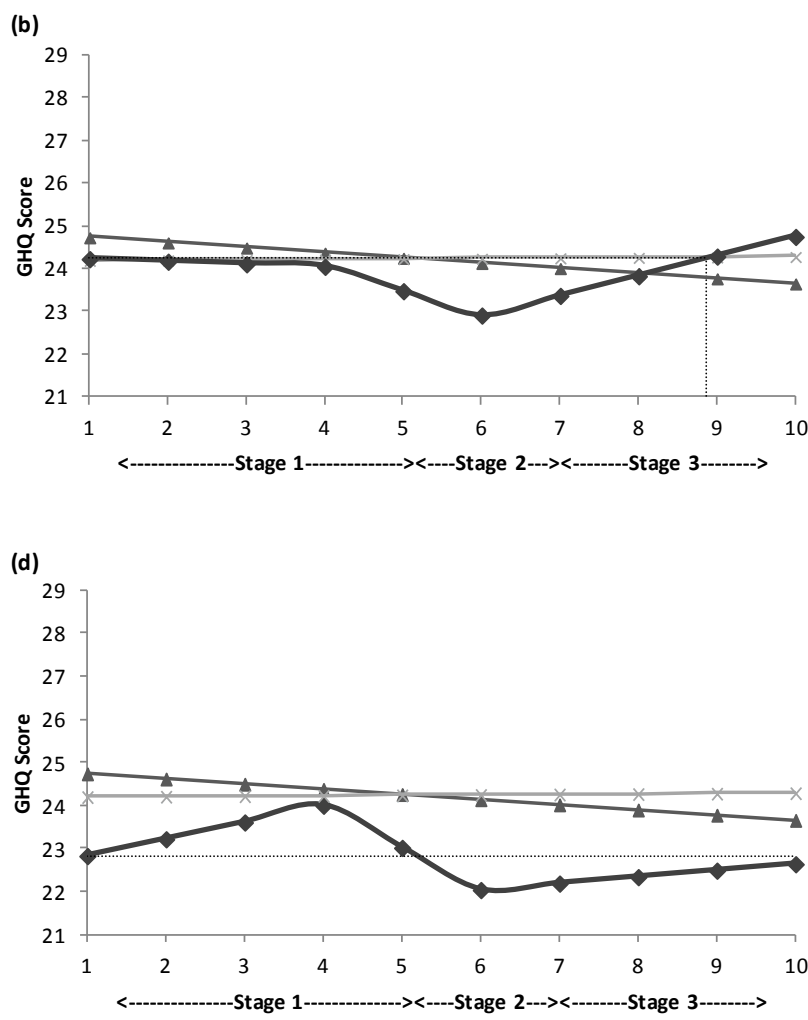

Upon employment, the life satisfaction of women IUE participants increased steadily, there were no significant changes to life satisfaction for men. The return to life satisfaction set point was 2.17 years for our female IUE exemplar respondent (Figure 5b).

Female IUI participants showed significant decline in life satisfaction during unemployment, but no significant increase on return to inactivity was observed (Figure 5d). Male IUI respondents however, did show a significant decrease in life satisfaction upon return to inactivity (Figure 4d). 
Figure 4. Life Satisfaction by labour force sequence growth curve models for men (- -): EUE (a), EUI (b), IUE (c) and IUI (d). Graph shows trend lines for continuously employed (- $-\Delta-$ ) and continuously economically inactive $(-x-)$ participants. The horizontal $(--)$ is the set point line and the vertical (--) is where the curve crosses the set point line, where applicable. The numbers along the $x$-axis are years.
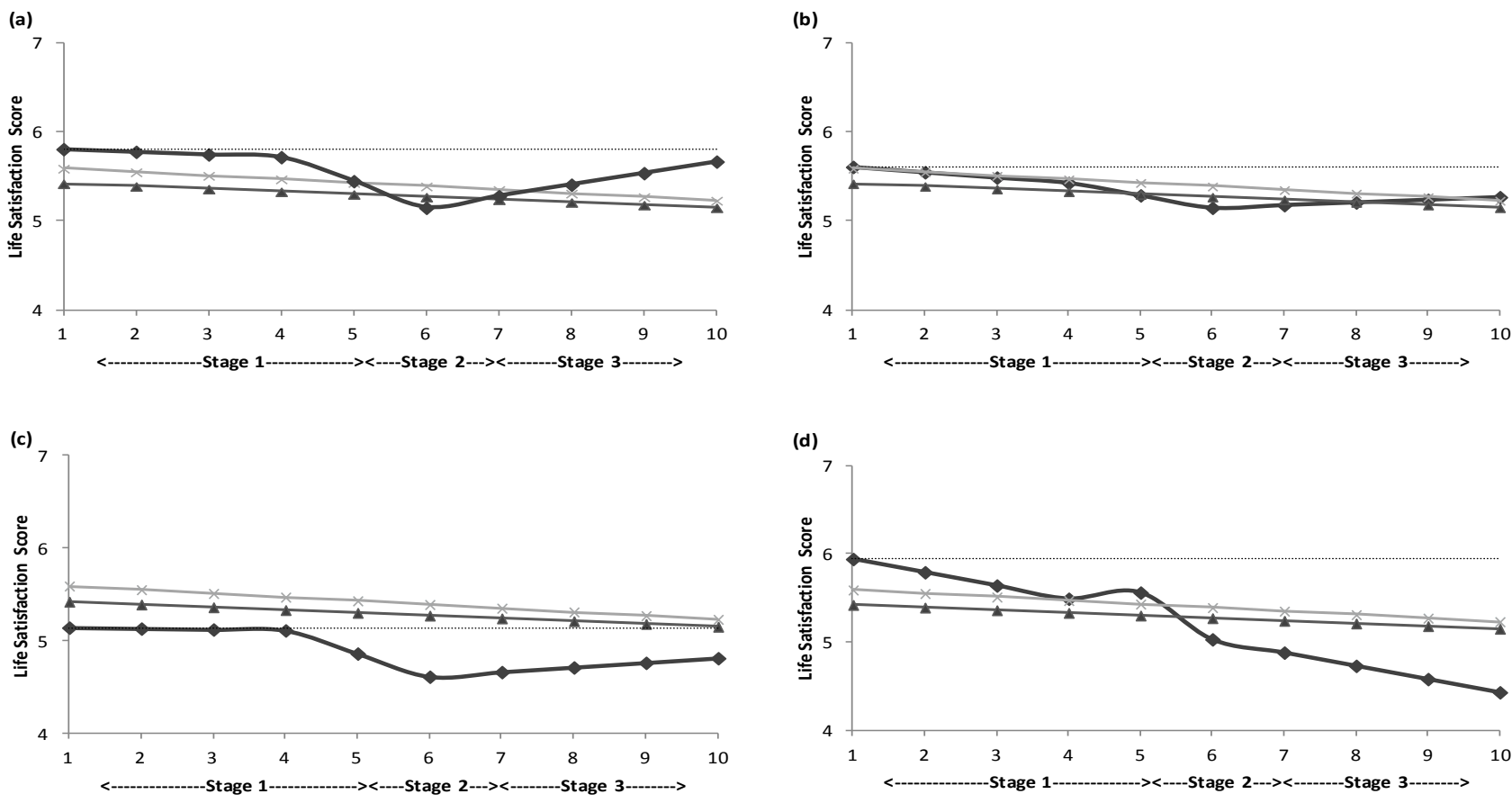

Figure 5. Life Satisfaction by labour force sequence growth curve models for women (- - -): EUE (a), EUI (b), IUE (c) and IUI (d). Graph shows trend lines for continuously employed $(-\Delta-)$ and continuously economically inactive (-x-) participants. The horizontal (--) is the set point line and the vertical (--) is where the curve crosses the set point line, where applicable. The numbers along the $x$-axis are years.
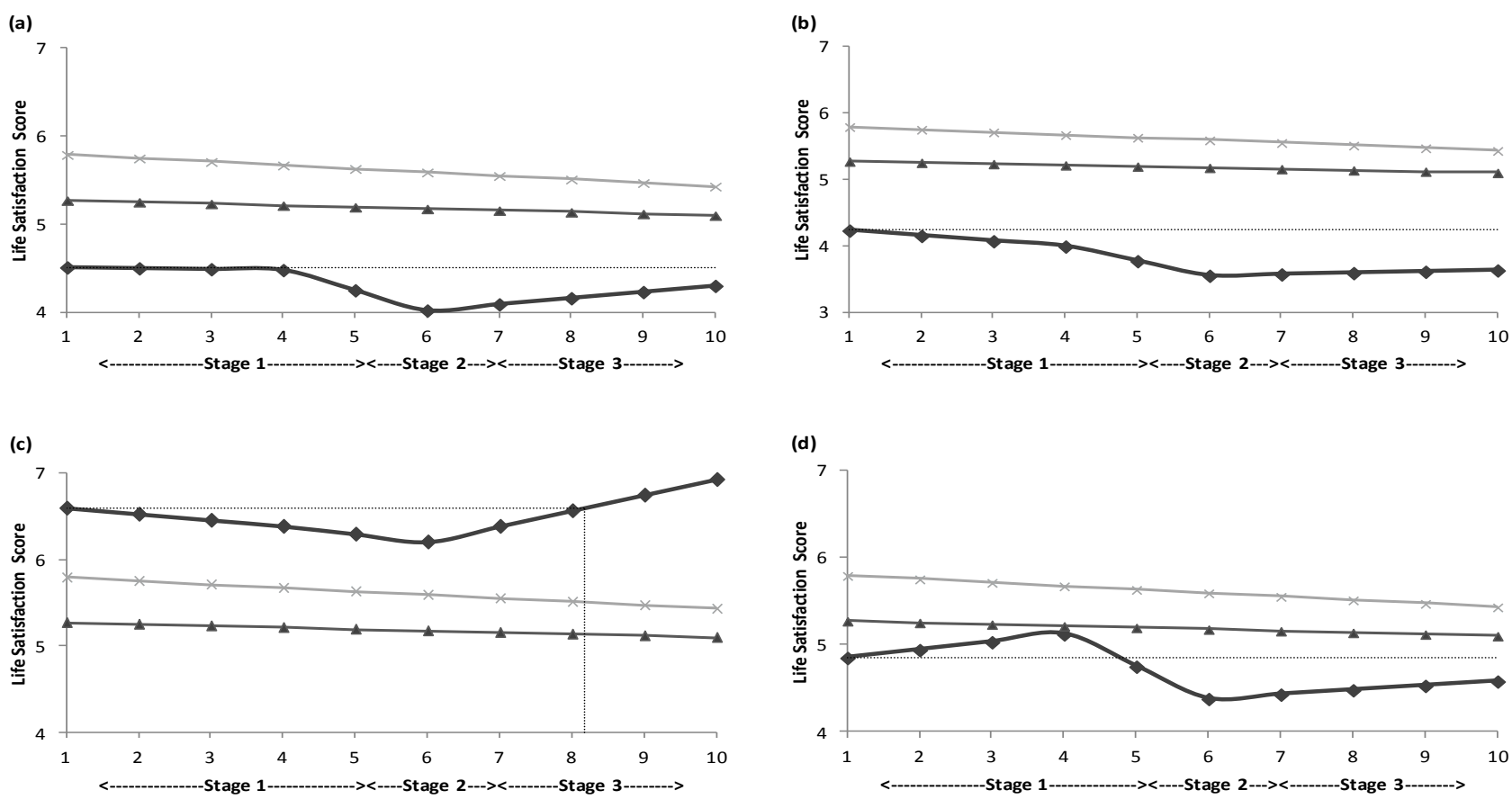
In addition to SWB trajectory differences by labour force sequence, we were able to explore SWB trajectories for selected economically inactive states, specifically retirement, family care, full-time student and long-term sick. In the overall models, only long-term sick respondents showed a significant increase in GHQ score postunemployment (See Table S2a in the supporting online Appendix B for parameter estimates). Participants who retired showed a significant decrease and those who became full-time students showed significant increases in life satisfaction upon exit from unemployment (See Table $\mathrm{S} 2 \mathrm{~b}$ in the supporting on-line Appendix B for parameter estimates). These findings did not change significantly by labour force sequence; EUI longterm sick were the only participants who experienced an increase in GHQ score upon their change from unemployment to long-term sick (See Table S3a in the supporting on-line Appendix C for parameter estimates). Both EUI and IUI participants experienced a decrease in life satisfaction upon retirement, i.e. post-unemployment, (See Tables S3a and S3b in the supporting on-line Appendix C for parameter estimates). Participants who were involved in family care showed a decrease in life satisfaction before becoming unemployed (IUE) (See Table S3c in the supporting on-line Appendix C for parameter estimates).

\section{Discussion}

\section{Main findings}

In the non-labour force sequence specific model, there was a return to GHQ and life satisfaction set points after exiting unemployment for both men and women. However, investigation of different labour force sequences showed variation in return to SWB set point. Men who entered economic inactivity after unemployment were much less likely to return to either their GHQ or life satisfaction set points, while men who exited to employment returned to both SWB set points. Conversely, women who exited to economic inactivity returned to their GHQ set point at a much faster rate than their life satisfaction set point. Differential changes in levels of distress and life satisfaction were observed upon further examination of types of economic inactivity. This finding provides evidence of the heterogeneity of the economically inactive and suggests that analysis of the effects of economic inactivity be stratified by type.

The revisions offered by Diener and colleagues (2006) are mainly supported by the findings from this study with potential new insights. While there was a return to the SWB set point in the overall model, the rate of return differed by labour force sequence as well as the measure of SWB. In general, both men and women included in this study had high levels of life satisfaction and lower levels of distress. The pre-unemployment distress levels of men and women were similar to those of the continuously employed or economically inactive. This pattern held for male life satisfaction, however women who experienced unemployment had lower life satisfaction pre-unemployment compared to continuously employed and economically inactive women. These findings support the idea that people are generally happy and positive as postulated by the first revision (Diener, Lucas, \& Scollon, 2006) rather than neutral per the hedonic treadmill (Brickman \& Campbell, 1971).

The second revision states that there are differences in the set points of individuals. This revision is supported by the finding of different levels of distress and life satisfaction at stage 1 for the different labour force sequences. While these differences may be small, larger differences can be seen between the set points of the different labour force sequences and those who were continuously employed or economically inactive. Men and women also appear to have different SWB set points. Similar differences for other life events, including marriage, divorce and disability were found by Lucas (2007a).

The finding that there were improvements in GHQ scores on exiting the labour market but no corresponding increase in life satisfaction for both men and women who experienced EUI supports the third revision. This revision states that there are multiple set points and that changes to these set points over time may not correspond due to the different dimensions of SWB (Diener, Lucas, \& Scollon, 2006). Further exploration of the economic inactivity state post-unemployment showed that participants who became long-term sick had a decrease in their distress levels with no corresponding change to their life satisfaction. Similar findings are seen in the IUE family care and IUI retired participants where there were significant 
reductions in life satisfaction while GHQ levels did not significantly change. The third revision suggests that returns to set points may occur for certain SWB domains but not for others, a finding observed with these data.

This study shows that overall there is a return to GHQ and life satisfaction set points following unemployment, however the time to return is affected by the labour force sequence experienced, with some sequences showing no return. This finding offers inconclusive support to the fourth hedonic treadmill revision, which states that set points can be altered. However some considerations need to be made which may increase support for this revision. One caveat is that the time to return to set point can vary, dependent on the length of unemployment. The figures in this paper provide a picture when a 2-year unemployment spell is experienced. In cases where SWB worsened during spells of unemployment, the length of unemployment spell becomes important. Taking into account any levelling-off effects, the longer one is unemployed, the longer it may take to return to set point. Experiencing multiple or repeated life events may also permanently alter the set point. Recent analysis of BHPS participants showed that those who experienced multiple unemployment spells following economic inactivity had worse reactions with each unemployment spell (Booker \& Sacker, 2011), making it less likely that these participants return to their SWB set point. The return to SWB set point may also be affected by national policies regarding unemployment and other social welfare benefits; these findings may not be universal phenomena. Additionally, for people who become employed after unemployment, the type of job may influence whether and how quickly they return to their SWB set point. If the post-unemployment job is of lower status or income or for fewer hours, then the return may be slower than if a person were to get a job appropriate for their qualifications and needs (Fineman, 1987).

Finally, Diener and colleagues offered a fifth revision to the hedonic treadmill, which states that adaptation varies across individuals. While this study did not specifically examine individual variations in adaptation, it did examine group differences in adaptation. Our findings showed faster rates of return to the GHQ set point for those participants who experienced IUE as compared to those who experienced EUE or EUI, and particularly slow adaptation was seen for IUI participants. Similar life satisfaction adaptation patterns differences were observed for women, while the time of return for IUE men was in between the time for EUE and EUI men. There were also differences between the two measures of SWB, and in some cases where there was a return to set point for one measure, there was not for the other measure. Additionally, there were differences in return to SWB set point by gender and by economic inactivity state, e.g. retirement compared with family care. One possible explanation for the lack of return to GHQ set point for men but not women is that their contribution to the total household income is larger. Therefore when men experience unemployment or enter economic inactivity, their increase in distress becomes so great that they are not able to return to their set point.

\section{Comparisons with previous studies}

Other studies (Lucas, 2007a; Lucas, Clarke, Georgellis, \& Diener, 2004; Luhmann \& Eid, 2009) have provided evidence of alterations to set point. Clark and colleagues (Clark, Diener, Georgellis, \& Lucas, 2008; Clark \& Georgellis, 2010) observed a slight return to set point among both British and German women who experienced unemployment, while there was no return for men in either country. In addition, full return to life satisfaction set points after experiencing other life events, such as marriage, divorce, birth of a child, etc., were observed for both men and women in these same studies (Clark, Diener, Georgellis, \& Lucas, 2008; Clark \& Georgellis, 2010). These differences in reactions to different life events raise the question of the generalisability of these findings to life events other than unemployment, and more research could explore whether there are differential changes to SWB set points for different life events. The effects of the combinations of these events should also be investigated. The cumulative or possibly synergistic effects of experiencing multiple life events within weeks or months of each other may greatly impact one's subjective wellbeing and whether a return to pre-event(s) set point is obtained. The sequence and anticipation of these events may also be important to the subjective well-being response. 


\section{Limitations}

There are some limitations to this study. First, the method in which the SWB and labour force status were measured may result in different rates of return to SWB set point. Labour force status was self-reported as the current status at the time of the interview. This means that a person could have experienced different labour force states throughout the year, which might impact on subjective well-being. The GHQ requires assessment of recent behaviours and emotions, while other SWB measures such as symptom checklists do not require comparisons to past behaviours. The return to set point may be different for a checklist than for the $\mathrm{GHQ}$, however symptoms were not measured in the BHPS.

Secondly, this study did not examine any potential moderators that could help to explain whether there are certain characteristics (e.g. coping skills, personal and household income and savings, potential earning capability, and personality) which allow people to return to their set point, either at all or faster than others. While other studies have shown differences in return to SWB set point between high and low earners (Georgellis, Gregoriou, Healy, \& Tsitsianis, 2008) and introverts and extraverts (Clark \& Georgellis, 2010) these studies have observed unemployment spells only and did not examine pre-unemployment labour force status. The findings from this study show differences in return to set point, and future studies could usefully address potential moderators of these effects.

Thirdly, we did not take into account the wider socio-economic context of the UK between 1991 and 2008. It is possible that unemployment which happened during a time of relative economic stability and low rates of unemployment, would be experienced differently from those spells occurring during a time of economic decline such as the post2008 'Great Recession'.

Finally, we did not examine what happens to people who experience more than one unemployment spell. The first, and in some cases only, unemployment spell experienced while enrolled in the BHPS was considered in this study. People who experience multiple unemployment spells may not return to the SWB level that was observed prior to the first unemployment spell, suggesting a permanent change in their set point. Nevertheless the variable indicating pre-study unemployment was not significant in all models for both outcomes, although there may still be some unknown variables that may affect the return to SWB set point. We do not know the time since prestudy unemployment spells, the labour force status before or after pre-study unemployment, or if there were any other life events which may have had an effect on an individual's SWB levels. Future studies should look at the effects of multiple exposures to different types of life events on subjective wellbeing set points.

\section{Conclusions}

This study has shown that the return to subjective well-being set point for men and women who experience a bout of unemployment, depends on the pre- and post-unemployment labour force sequence experienced and the SWB outcome examined. Men who became employed following a period of unemployment were more likely to return to their pre-unemployment SWB set points, while men who entered economic inactivity did not. Conversely, while women were likely to return to their SWB set points, the return to GHQ set point was quicker than their return to life satisfaction set point. Examination of the specific types of economic inactivity produced interesting patterns. Participants who retired also experienced a reduction in life satisfaction while participants who became economically inactive due to long-term health problems had a reduction in psychological distress. Current changes of and debates over governmental policies worldwide, to increase retirement age and decrease the number of economically inactive persons may have the unintended consequence of adversely impacting on levels of subjective well-being in this population group. Finally, time to return to SWB set point may vary with the duration of unemployment.

These findings suggest that an increased understanding of the effects of different types of economic inactivity on subjective well-being is indicated. Researchers and policy makers should address the psychological impacts and potential further health risks due to entering economic inactivity, particularly among men. 


\section{Acknowledgments}

The support of both the Economic and Social Research Council (ESRC) and the University of Essex is gratefully acknowledged. Data from the British Household Panel Survey (BHPS) were supplied by the ESRC Data Archive. This research was supported by the ESRC Research Centre on Micro-Social Change (MISOC), ESRC References Number RES-535-25-0090 and the ESRC International Centre for Lifecourse Studies in Society and Health, ESRC References Number RES-596-28-0001.

\section{References}

Beatty, C., Fothergill, S., \& Macmillan, R. (2000). A theory of employment, unemployment and sickness. Regional Studies, 34, 617-630.

Bollen, K. A., \& Curran, P. J. (2006). Latent Curve Models: A Structural Equation Perspective. Hoboken, NJ: John Wiley \& Sons, Inc.

Booker, C. L., \& Sacker, A. (2012). Psychological well-being and reactions to multiple unemployment events: Adaptation or sensitisation? Journal of Epidemiology and Community Health, 66, 832-838.

Brickman, P., \& Campbell, D. T. (1971). Hedonic Relativism and Planning the Good Society. In M. H. Appley (Ed.), Adaptation Level Theory: A Symposium. (pp. 287-302). New York: Academic Press.

Chou, C.-P., Yang, D., Pentz, M. A., \& Hser, Y.-I. (2004). Piecewise growth curve modeling approach for longitudinal prevention study. Computational Statistics \& Data Analysis, 46, 213-225.

Clark, A. E., Diener, E., Georgellis, Y., \& Lucas, R. E. (2008). Lags and leeds in life satisfaction: A test of the baseline hypothesis. Economic Journal, 118, F222-F243.

Clark, A. E., \& Georgellis, Y. (2010). Back to baseline in Britain: Adaptation in the BHPS. Working Paper No. 2010-02. Paris: Paris School of Economics.

Clark, A. E., Georgellis, Y., \& Sanfey, P. (2001). The psychological impact of past unemployment. Economica, $68,221-241$.

Deaton, A. (2008). Income, health and well-being around the world: Evidence from the Gallop World Poll. Journal of Economic Perspectives, 22, 53-72.

Diener, E. (2000). Subjective well-being: The science of happiness and a proposal for a national index. American Psychologist, 55, 34-43.

Diener, E., \& Emmons, R. A. (1984). The independence of positive and negative affect. Journal of Personality \& Social Psychology, 47, 1105-1117.

Diener, E., Lucas, R. E., \& Scollon, C. N. (2006). Beyond the hedonic treadmill: Revising the Adaptation Theory of Well-being. American Psychologist, 61, 305-314.

Diener, E., Suh, E. M., Lucas, R. E., \& Smith, H. L. (1999). Subjective well-being: Three decades of progress. Psychological Bulletin, 125, 276-302.

Fineman, S. (1987). Back to employment: Wounds and wisdom. In D. Fryer \& P. Ullah (Eds.), Unemployed People (pp. 268-284). Milton Keynes: Open University Press.

Frederick, S., \& Loewenstein, G. (1999). Hedonic adaptation. In D. Kahneman, E. Diener \& N. Schwarz (Eds.), Well-being: The foundations of hedonic psychology. (pp. 302-329). New York: Russell Sage Foundation.

Georgellis, Y., Gregoriou, A., Healy, J., \& Tsitsianis, N. (2008). Unemployment and life satisfaction: A nonlinear adaptation process. International Journal of Manpower, 29, 668-680.

Goldberg, D., \& Williams, P. (1988). A User's Guide to the General Health Questionnaire. Windsor: NFERNelson.

Goldberg, D., \& Williams, P. (1991). A User's Guide to the General Health Questionnaire. London: NFERNelson.

Goldberg, D. P., Gater, R., Sartorius, N., Ustun, T. B., Piccinelli, M., Gureje, O.,\& Rutter, C. (1997). The validity of two versions of the GHQ in the WHO study of mental illness in general health care. Psychological Medicine, 27, 191-197.

Headey, B. (2006). Subjective well-being: Revisions to dynamic equilibrium theory using national panel data and panel regression methods. Social Indicators Research, 79, 369-403.

Headey, B. (2008a). Life goals matter to happiness: A revision of set-point theory. Social Indicators Research, $86,213-231$.

Headey, B. (2008b). The set-point theory of well-being: Negative results and consequent revisions. Social Indicators Research, 85, 389-403.

Headey, B., \& Wearing, A. (1992). Understanding Happiness: A Theory of Subjective Well-being. Melbourne: Longman Cheshire.

Lucas, R. E. (2005). Time does not heal all wounds: A longitudinal study of reaction and adaptation to divorce. Psychological Science, 16, 945-950. 
Lucas, R. E. (2007a). Adaptation and the set-point model of subjective well-being: Does happiness change after major life events? Current Directions in Psychological Science, 16, 75-79.

Lucas, R. E. (2007b). Long-term disability is associated with lasting changes in subjective well-being: Evidence from two nationally representative longitudinal studies. Journal of Personality \& Social Psychology, 92, 717-730.

Lucas, R. E., Clark, A. E., Georgellis, Y., \& Diener, E. (2003). Reexamining adaptation and the Set Point Model of happiness: Reactions to changes in marital status. Journal of Personality \& Social Psychology, 84, 527-539.

Lucas, R. E., Clarke, A. E., Georgellis, Y., \& Diener, E. (2004). Unemployment alters the set point for life satisfaction. Psychological Science, 15, 8-13.

Luhmann, M., \& Eid, M. (2009). Does it really feel the same? Changes in life satisfaction following repeated life events. Journal of Personality \& Social Psychology, 97, 363-381.

OECD. (2010). OECD Factbook 2010: Economic, Environmental and Social Statistics: OECD Publishing.

OECD. (2011). OECD Better Life Initiative. Retrieved June 06, 2011., from http://www.oecdbetterlifeindex.org/

SAS Institute Inc. (2003). SAS/STAT Software (Version 9.2). Cary, NC.

Taylor, M. F., with Brice, J., Buck, N., \& Prentice-Lane, E. (Eds.). (2009). British Household Panel Survey User Manual Volume A: Introduction, Technical Report and Appendices. Colchester: University of Essex. 